\title{
Teaching Folder Management System for the Enhancement of Engineering and Built Environment Faculty Program
}

\author{
Mohammad Syuhaimi Ab-Rahman ${ }^{1}$, Muhamad Azrin Mohd Mustaffa ${ }^{1}$, Nasrul Amir Abdul ${ }^{1}$, \\ Abdul Rahman Mohd Yusoff ${ }^{1} \&$ Afiq Hipni ${ }^{1}$ \\ ${ }^{1}$ Quality Assurance Office, Faculty of Engineering \& Built Environment, National University of Malaysia, \\ Malaysia \\ Correspondence: Mohammad Syuhaimi Ab-Rahman, Quality Assurance Office, Faculty of Engineering \& Built \\ Environment, National University of Malaysia, 43650 UKM Bangi Selangor, Malaysia. Tel: 60-3-8921-6837. \\ E-mail: syuhaimi@eng.ukm.my
}

Received: December 23, 2014 Accepted: February 22, 2015 Online Published: June 29, 2015

doi:10.5539/ies.v8n7p204 URL: http://dx.doi.org/10.5539/ies.v8n7p204

\begin{abstract}
A strong, systematic and well-executed management system will be able to minimize and coordinate workload. A number of committees need to be developed, which are joined by the department staffs to achieve the objectives that have been set. Another important aspect is the monitoring department in order to ensure that the work done is correct and in line with the Washington Accord's requirements. A strong academic management system consists of four main sections namely activities organization and evaluation, documentation system, ongoing improvement and information sharing. This paper focuses on the importance of the third aspect, which is the documentation system. It is crucial to establish a systematic and efficient documentation system that reflects all the efforts that have been done in the program courses. The Faculty of Engineering and Built Environment of Universiti Kebangsaan Malaysia (The National University of Malaysia) has taken a number of measures in upgrading its document management. The performance of teaching folder submission has increased significantly for all departments.
\end{abstract}

Keywords: documentation, EAC, internal audit, quality assurance, teaching folders

\section{Introduction}

Teaching folder is considered one of important documentation for teaching and learning process in Universiti Kebangsaan Malaysia (The National University of Malaysia). It becomes an obligation of all lecturers to prepare a complete teaching folder every semester. All of these folders need to be completed according to the format that has been agreed. Those folders will be orderly kept in an orderly secured cabinets, categorized every semester and place in faculty's Quality Assurance Office.

Lecturers are allowed to borrow these folders for reference purpose which needs to be recorded. The period for these folders allowed to be borrowed is within 7 days. Each folder is attached with a checklist that was approved by the Faculty of Engineering and Built Environment to make it more convenient for lecturers to insert the required information. The Quality Assurance staff will check all the folders to ensure that all mandatory information was attached. This folder can be used as reference for other lecturers for the requirement of course folder which later will be audited internally by internal auditors and Engineering Accreditation Council (Jensen, 2000).

These teaching folders can become reference for lecturer to check each course requirements. They will be audited by internal auditors during Engineering Accreditation Council (EAC) audit process. In order to maintain in high working standard environment, the FKAB Quality Assurance Office will constantly monitoring and ensuring that every lecturer is complying with the quality practices. On top of it, the office welcomes any comment or suggestions and improvement of FKAB Teaching Folders System.

Based on observation, there are three main problems that are related to teaching folders which are (i) the performance does not match the actual distribution marking; (ii) incomplete and in consistency of document and (iii) non submission of folders (where a few teaching folders were not submitted to the Quality Assurance Office).This paper tend to share improvement that have been made on the teaching folder management system at 
our Faculty of Engineering and Built Environment in order to minimize the problem related to teaching folders.

\section{The Importance of Teaching Folder Management}

The increase in lecturers' workload is caused by unsystematic and unintegrated documentation system (Phillips et al., 2000). The documentation and filing system at every department needs to be improved and fully utilized not only for better retrieving but most importantly during any audit or accreditation purpose. The most important thing is to coordinate the filing system at every department (Paramasivam et al., 2013). Folders that are related to accreditation material, committee meeting, Continuous Quality Improvement (CQI), activities with external parties such as industry, Industrial Advisor Panel (IAP) and alumni need to be developed. Internal audit is one of the most important certification process for an institution and viewed as a monitoring and compliance function focused on assisting reliable accounting information and to protect institution assets (Arena, 2013). All committees and their members need to be informed and advised to make a copy of the documentation for record purpose. Figure 1 shows the filing system that is practiced at the Faculty of Engineering and Built Environment of The National University of Malaysia involving five departments namely the department of (i) Civil \& Structural Engineering (JKAS); (ii) Electrical, Electronics \& System Engineering (JKEES); (iii) Mechanical \& Material (JKMB); (iv) Chemical \& Process Engineering (JKKP); and (v) Architecture (JSB).

Objectives of Coordination and Value Add filing system are as follows:

1) Coordinating Departments' management folders for easy access by external bodies (Quality Assurance Office and Faculty) (Issa, 2000).

2) Simplifying monitoring process by the Quality Assurance Office for audit preparation

3) Ensuring that all the folders are available in the departments and completely filled under the appropriate codes Importance of Course Folder Management:

1) Enabling easy access and monitoring

2) Ensuring the contents is complete as teaching and learning record

3) Record for improvement and monitoring process

4) Abiding by the ISO work orders (Cheng et al., 2004; Hernad \& Gaya, 2013)

Strategy and Requirement:

1) Contents listing

2) Coordinated contents

3) Course improvement and monitoring

4) Labeling for easy access

\section{Efforts Done in the Management of Documents Storage}

\subsection{Upgrading the Presentation of Teaching Folders}

Colour is chosen to differentiate the type and ownership of teaching folders. For example, different work order folders are distinguished by different colours, as shown in Picture 1. This also applies to the ownership (in which department the folders belong). The folders are also differentiated according to semesters. Partition pages are included in the folders so that the lecturers will notice which documents to attach inside the folders. Examples of the upgraded folders are shown in Picture 2 and its content partition was shown in Picture 3. The folders are also coded with numbers to make it easier for monitoring and auditing purpose, which is apparent in Picture 4 . The cabinets holding the folders are labeled for easily access and systemize the folder management as shown in Picture 5. 


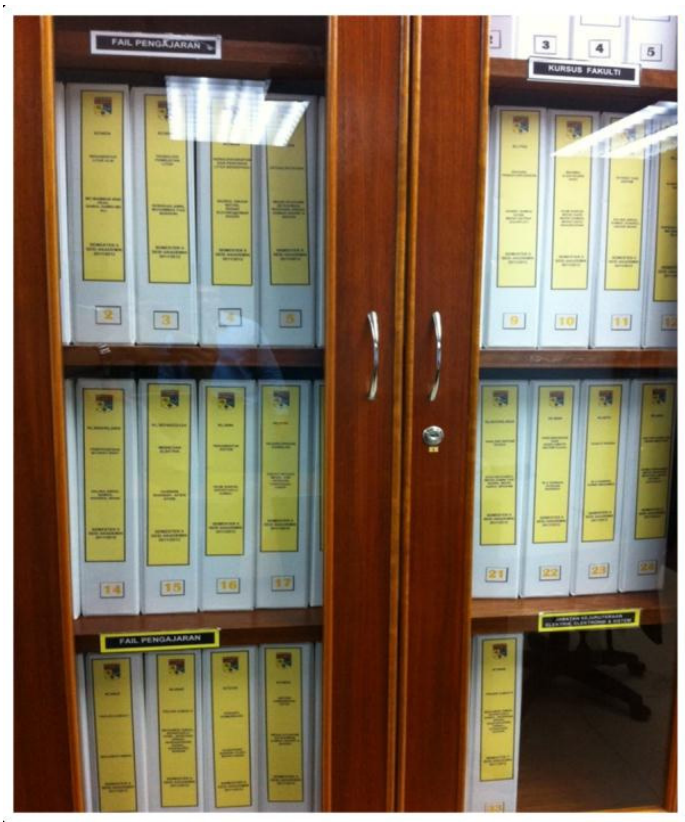

(a)

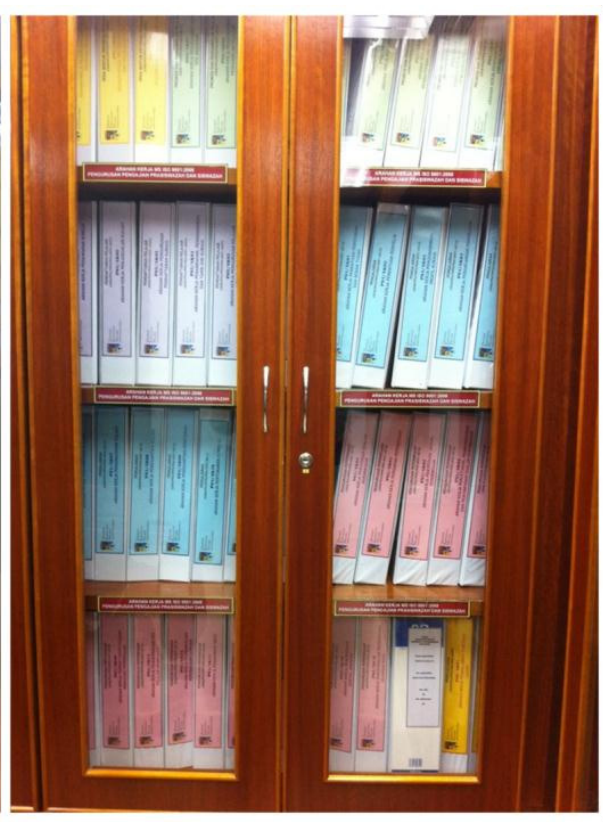

(b)

Picture 1. (a)Folders kept in special cabinet (b) Segregation of documentation folders

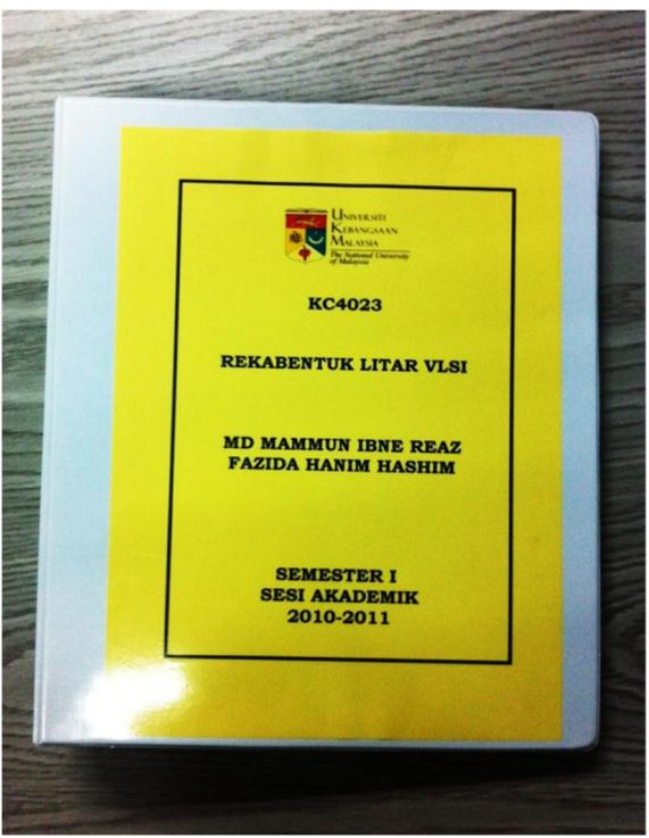

(a)

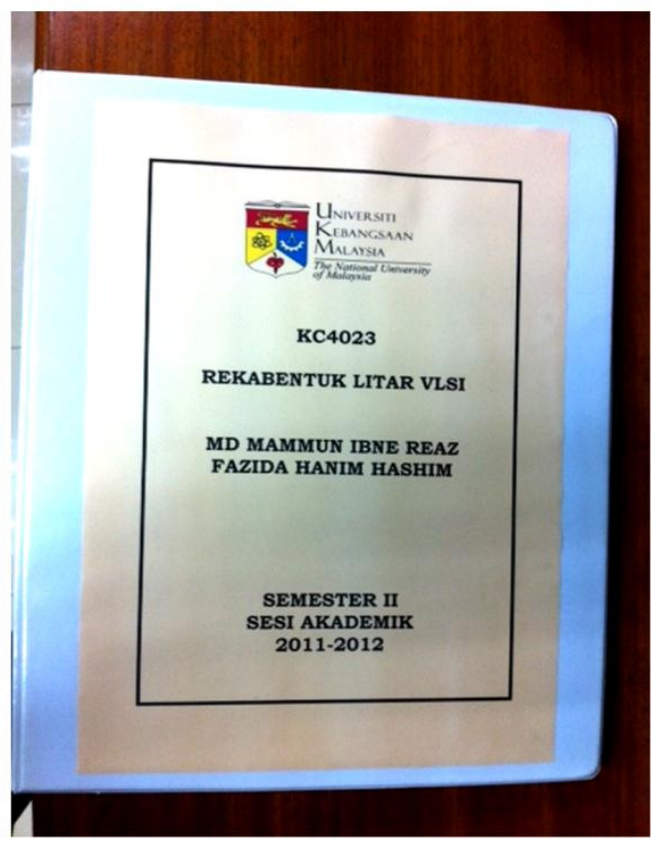

(b)

Picture 2. Front cover of teaching folders using colour paper, according to respective JKEES department (a) Yellow for courses in 1 st semester and (b) Orange for 2nd semester 


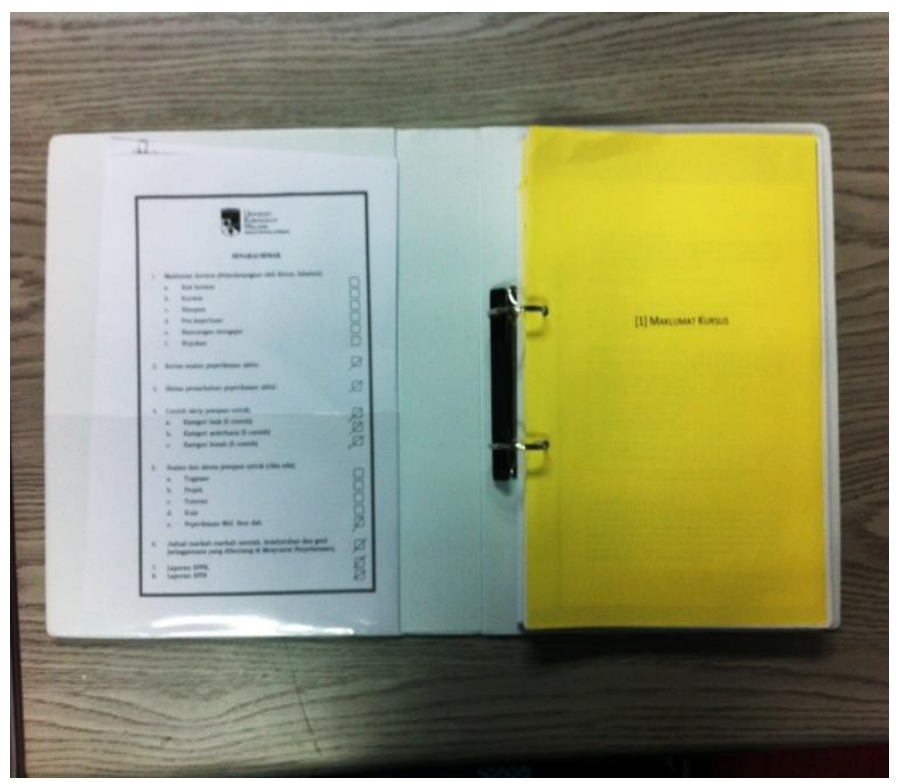

Picture 3. Partitionis used to separate contents of the folder

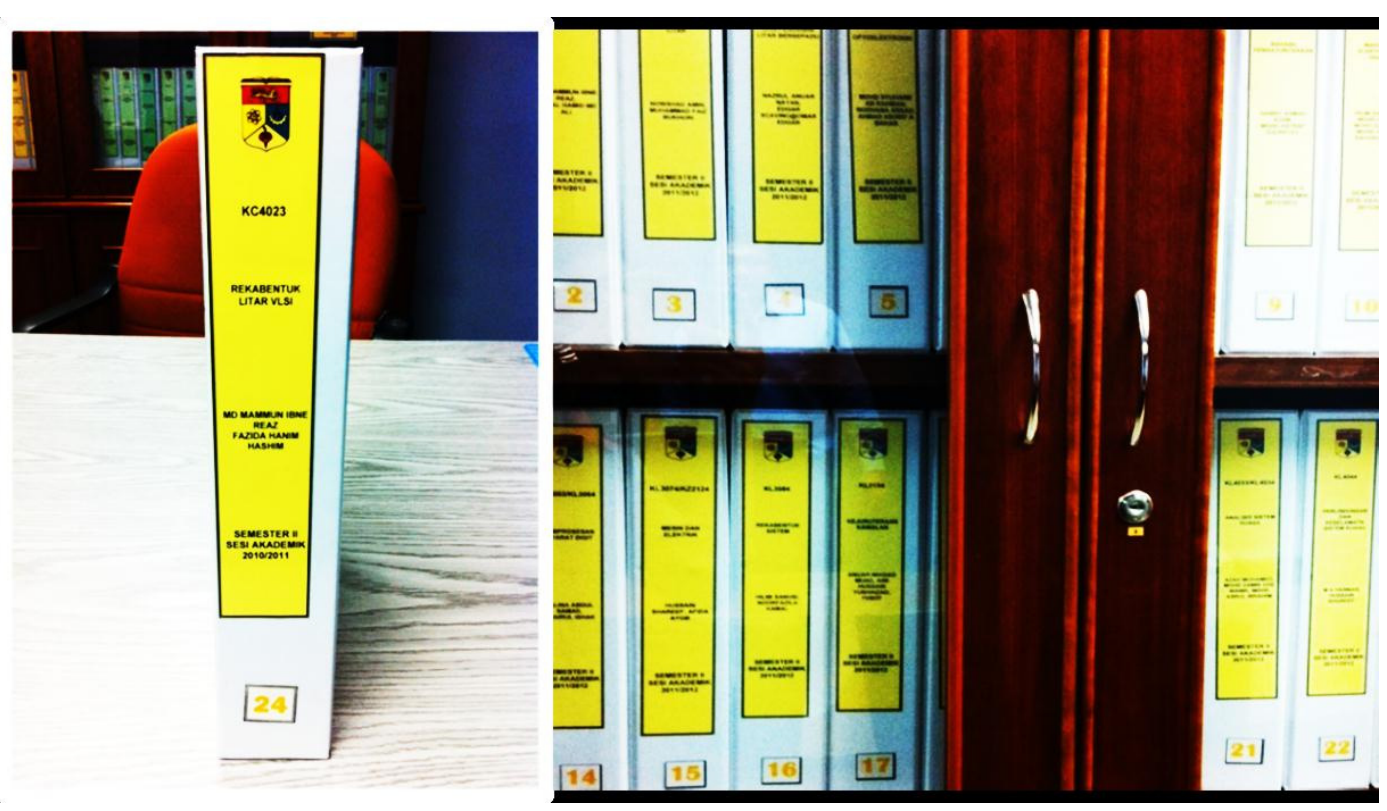

Picture 4. Vertical side labels are used for easier folder searching 


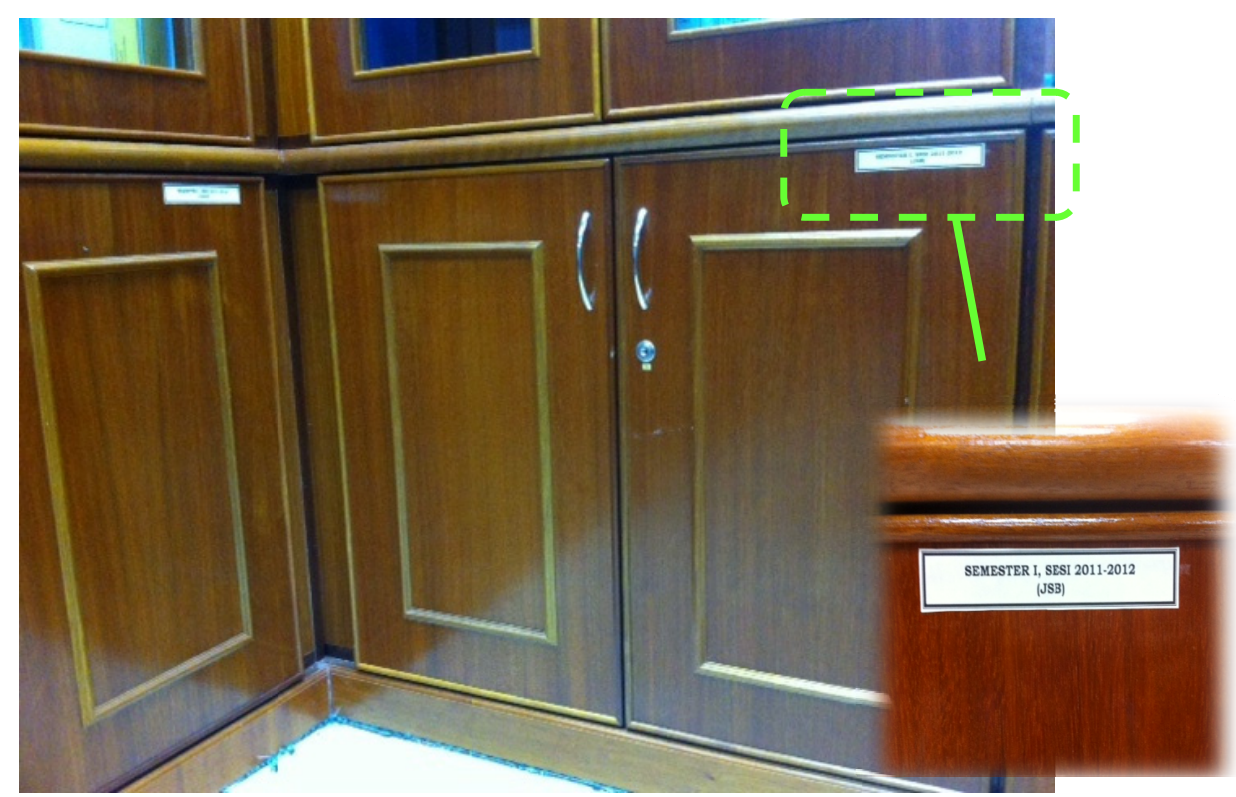

Picture 5. Labels attached to cabinet for storing teaching folders from previous semester

Table 1. Different teaching folders colours for different departments

\begin{tabular}{lll}
\hline No. & Department & Colour \\
\hline 1 & Faculty & White (Semester 1) + Light purple( Semester 2) \\
2 & JKKP & Light green (Semester 1) + Dark green (Semester 2) \\
3 & JKEES & Yellow (Semester 1) + Orange (Semester 2) \\
4 & JKMB & Light blue (Semester 1) + Dark blue (Semester 2) \\
5 & JKAS & Pink (Semester 1) + Red (Semester 2) \\
6 & JSB & Light brown (Semester 1) + Dark brown (Semester 2) \\
\hline
\end{tabular}

\section{Improvement of Teaching Folder Process Chart}

The chart below shows the teaching folder process that has been updated. This will be a standardized process flow to ensure the success of the objective of this effort. 
The faculty sends out letters to the departments to inform that the teaching folders will be delivered to every department.

The department distributes the folders to the lecturers.

Each department collects the complete folders and these are inspected and validated by the Head of Department.

The Quality Unit receives the complete folders and labels them after thorough inspection.

A report is prepared by the Quality Unit Assurance on the status of Incomplete Folders (ICF) and Non Submitted Folders (NSF).

The Quality Assurance unit returns incomplete folders to the respective departments to be completed. ICF and NSF reports are submitted to the departments for further action.

Completed folders are stored in controlled documents room in the Quality Assurance Unit's office.

Figure 1. Teaching folders submission and inspection process

\section{Updating and Coordination of the Teaching Folders Checklist Form}

Checklist form for all undergraduate and postgraduate course folders has been inspected and updated. The system has been implemented since Semester 1, Session 2012/2013. All departments are required to prepare the Course Assessment Report to make it a standardized accreditation format.

For the postgraduate program, a standardFollow Up FormCoursesTeaching and Learning Improvement (B1) will be used to inform any improvement step that have been done. This form can be used as reference in teaching and learning for courses that were taught compared to the previous session. Any improvement is based on the feedback/complaint in Teaching and Supervision Evaluation System (SPPP) received from the previous session. The above listed forms areshown in Figure 2, Figure 3 and Figure 4.

\section{Marks Distribution Forms}

In order to ensure actual examination marks distributed is similar to the course perform, a confirmation form between the perform and the achievement mark is developed. In order to confirm, those results need to be signed by every lecturer and validated by the head of department. This form is filled up upon attending final grade coordinating meeting. It was enforced since Semester 1 2012/2013. The form will be kept in the Examination Folder in every department. The example for this form is shown in Figure 5. 


\section{TEACHING FOLDER CHECKIIST (UNDERGRADUATE COURSE)}

1. Course Information:

a. Course synopsis based on Grideline Book according to students intake session (any change requires the Head of Department's validation)

b. Teaching plan

c. MarkingDistribution

d. Improvements that have been executed - Follow Up Action Fonm for Improvement (FKAB/BI) (ffapplicabik)

2. Final Examination:
a. Question paper
b. Examination Question Bloom Taxonomy
c. Examination answer scheme
d. Examination answer scriptsamples
i. Good (3 samples)
ii. Intermediate (3 samples)
iii. Weak (3 samples)

3. Question (if contributing to final mark).
a. Mid-term Examination
b. Tutorial
c. Project
d. Quiz and others

4. Overall mark and grade table similar to the marking distribution suggestion in the course information (matter lC) and has been presented during the Grade Coordination Meating

5. Students Attendance Verification (if applicable)

6. Course Evaluation Report

7. SPPP Report

Figure 2. Checklist for items required for undergraduate course teaching folders 


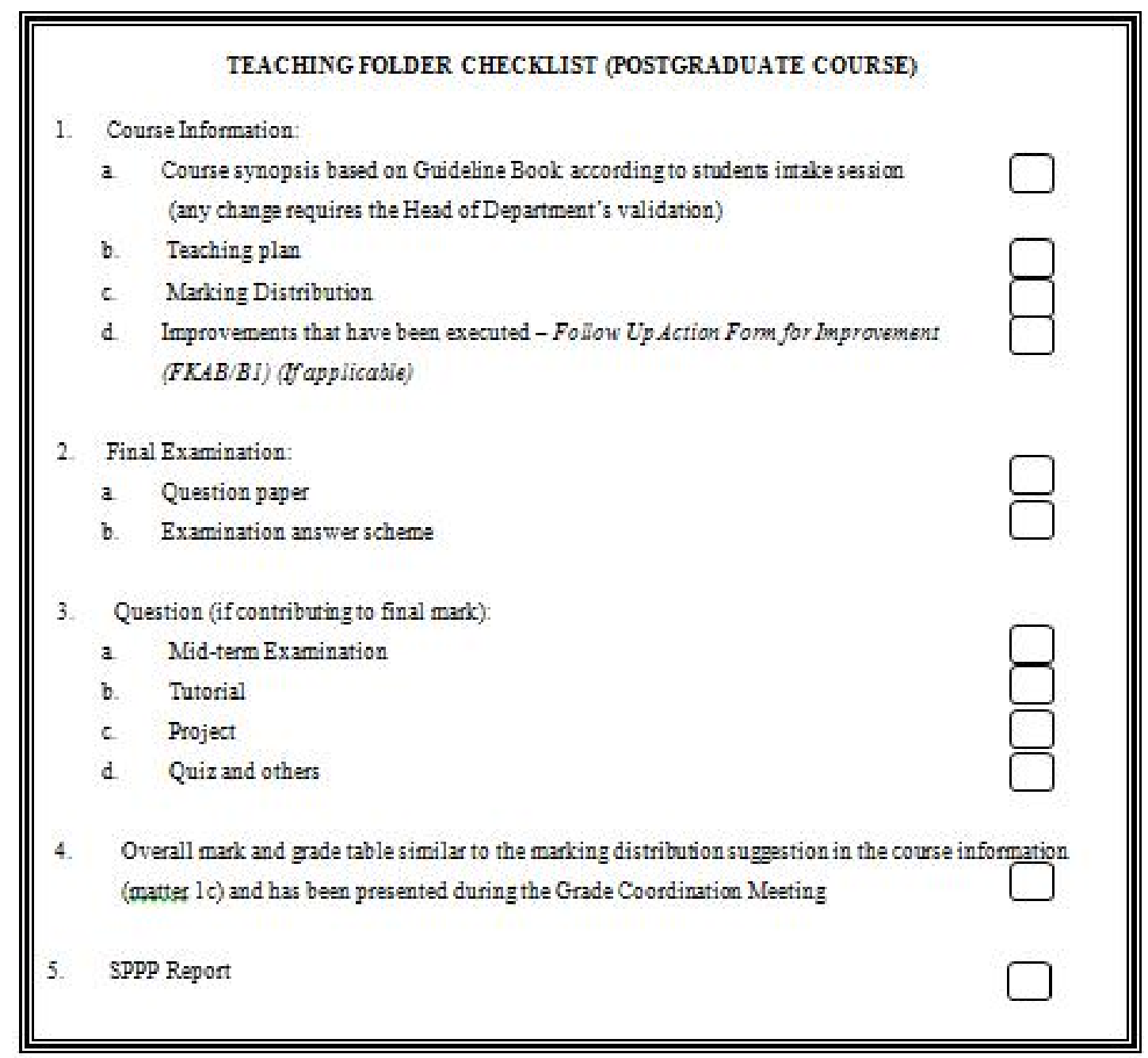

Figure 3. Checklist for items required for postgraduate course teaching folders 


\section{FOLLOW UP ACTION FOR IMPROVEMENT OF COURSE LEARNING AND TEACHING}

Note: This fonn is filled in for the purpose of notifing any inprovement step that has been executed as a P\&P implementation plan for the taught course compared to the previous session. Example of inprovement is based on feedback/comment in previous session SPPP.

CODE OF COURSE:

NAME OF LECTURER:

DEPARTMENT / PROGRAM:

SEMESTER:

IMPROVEMENT P\&PDONE:

(Please mark and state the improvement if applicable)

Based on own initiative

Based on previous feedback such as SPPP/extemal evaluation, etc

Course's Lecturer's Signature and Stamp

Date:

Figure 4. Checklist items required for postgraduate course teaching folders 


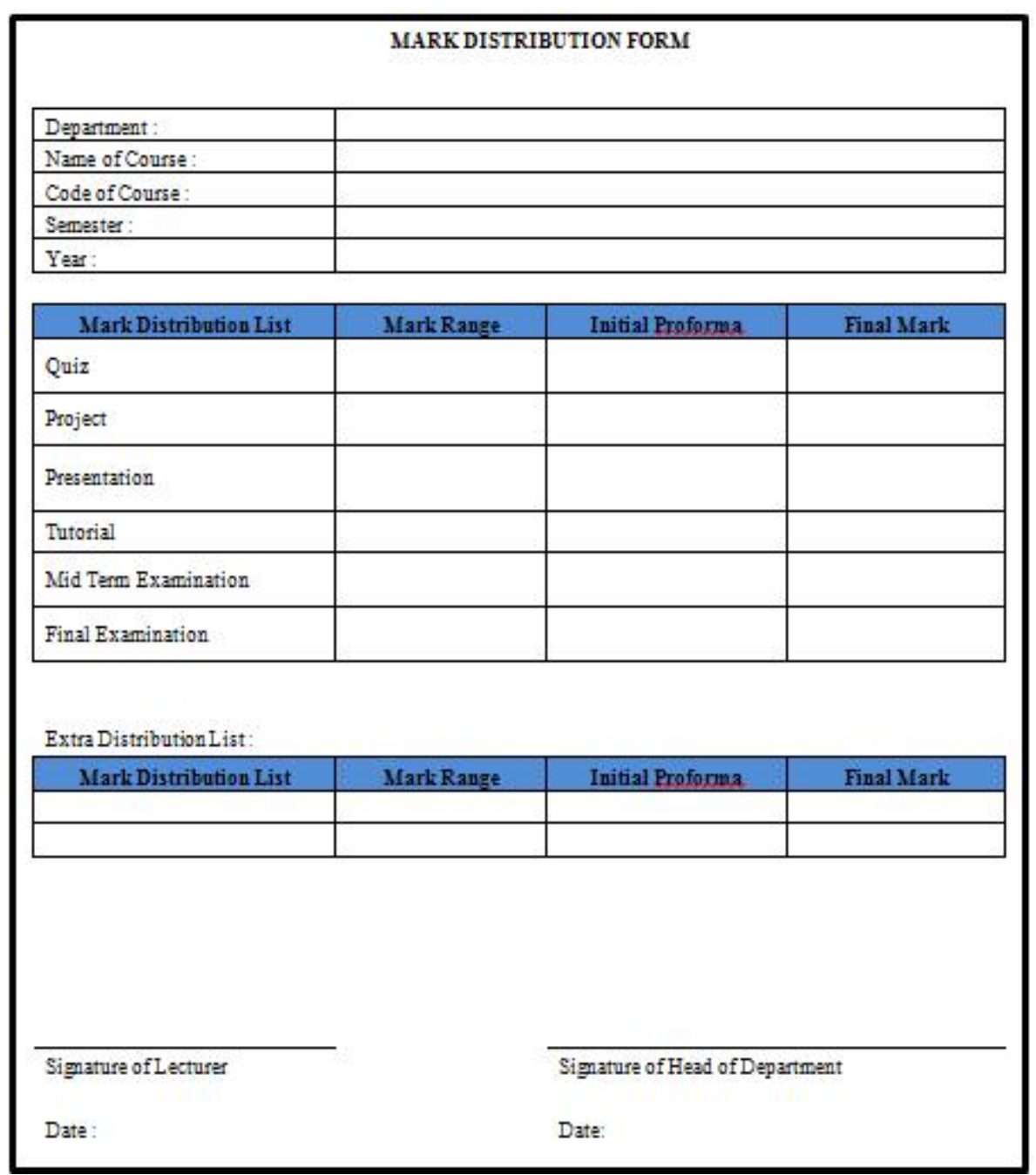

Figure 5. Mark distribution form

\section{Conclusion and Discussion}

Figure 7 shows an increase in the performance of teaching folders submission within lecturer for 2012/2013 first semester undergraduate courses compared to the analysis in Figure 6 for 2011/2012 second semester. All five departments show an increase in the percentage of complete teaching folders submission, and one of the most obvious cases is shown by the Department of Mechanical \& Material Engineering (JKMB) with a $30 \%$ increase. Meanwhile, the Department of Electrical, Electronics \& System (JKEES) achieved perfect score in the submission of complete teaching folders. This is a good achievement because there was no record of $100 \%$ complete teaching folders submission in the previous years. 


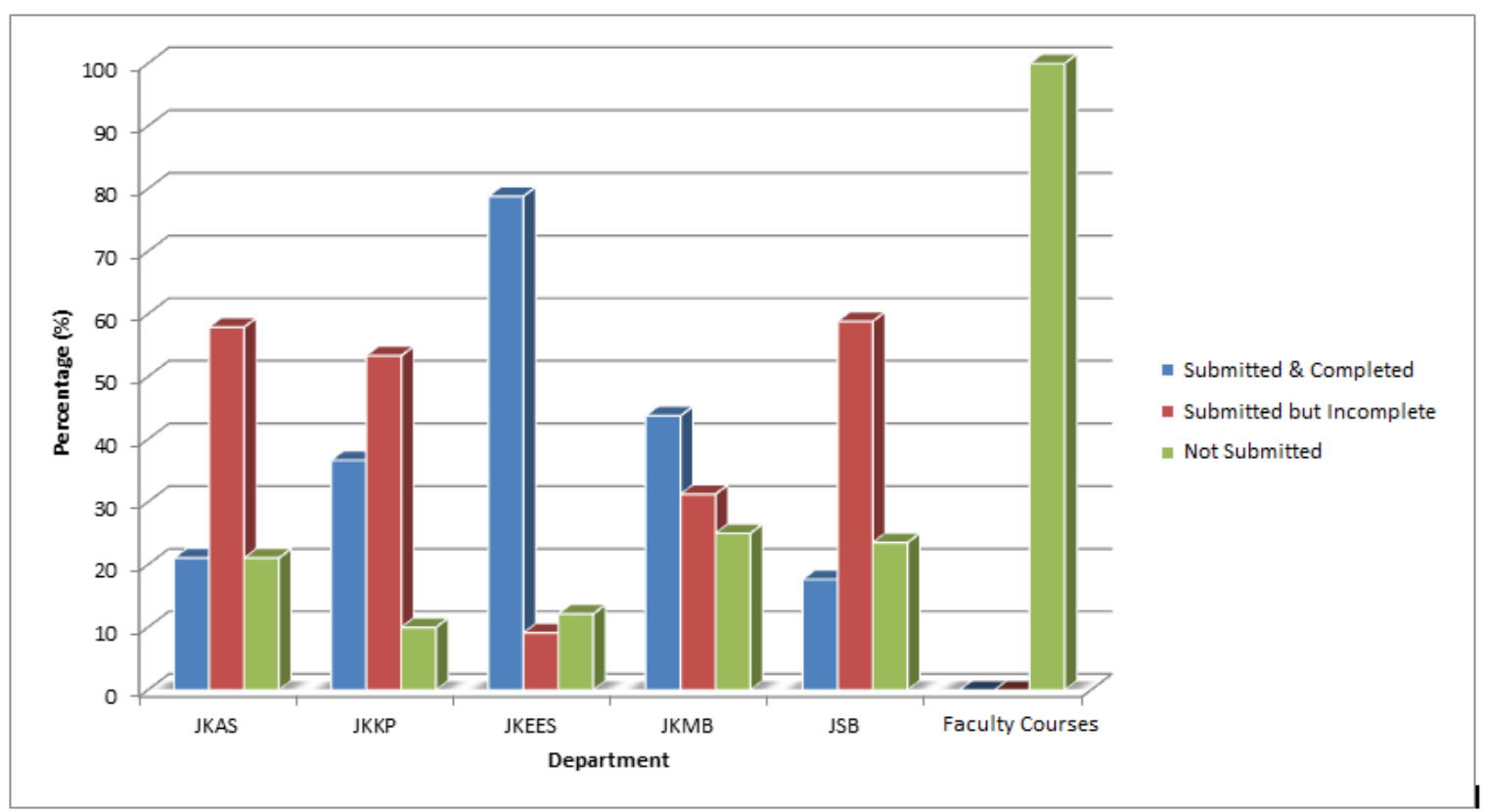

Figure 6. Percentage of teaching folders submission for FKAB 2011/2012 second semester undergraduate courses

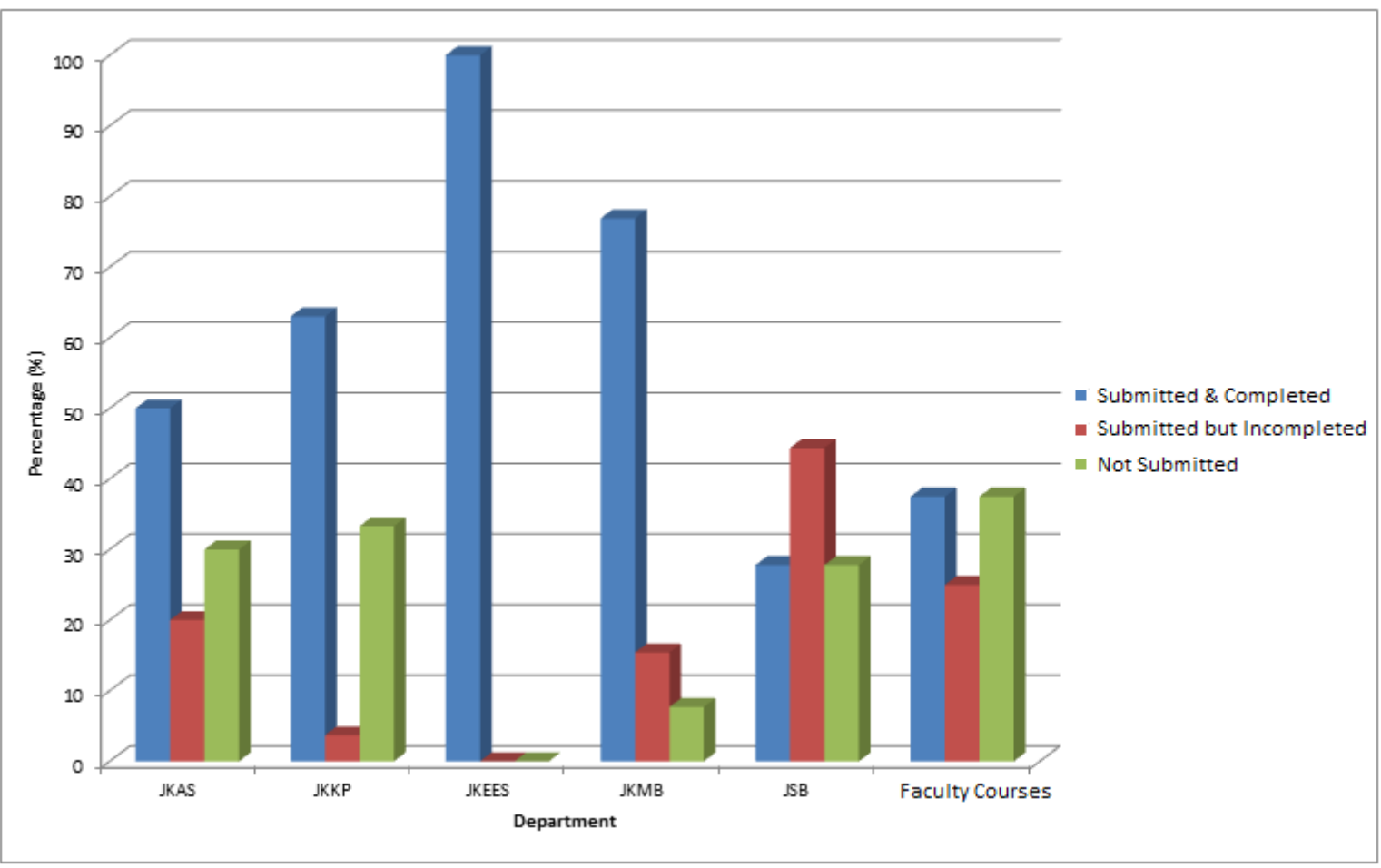

Figure 7. Percentage of teaching folders submission for FKAB 2012/2013 first semester undergraduate courses

There is also a decrease in the submission of incomplete teaching folders for all five departments except for faculty courses. The percentage of non-submission of folders also decreases for these three departments namely JKEES, JKMB and faculty courses. The Department of Civil \& Structural Engineering (JKAS), the Department of Chemical \& Process Engineering (JKKP) and the Department of Architecture (JSB) still show a slight increase in the percentage of non-submission of teaching folders. These cases are usually caused by a small number of academic staffs who are still not awarethe importance of teaching folder system. Furthermore, no 
strict action has been taken on them even though this problem has reoccurred for few semesters. Non-submission of teaching folders will give a bad record for the faculty during accreditation audit by the EAC and Washington Accord. Two most common mistakes done by lecturers are (i) not ensuring the marking plan is not similar to that of final marks and (ii) attaching the wrong documents inside the teaching folders (Example: Attaching mid-term examination answer scripts as opposed to student's project). Academic staffs need to ensure that the materials attached in the teaching folders are the correct ones, according to the standard checklist. A perfect and completed teaching folder can be made as a reference for others to follow. All teaching folders have a standard items and materials which will make it easier for auditors to inspect. One of the most effective method used to ensure teaching folders submitted are complete and perfect manner is by enforcing strict action. With the enforcement, that will affect the staff performance of those who did not follow the instruction. This action should be taken after warning has been issued by the top management such as the Dean's office.

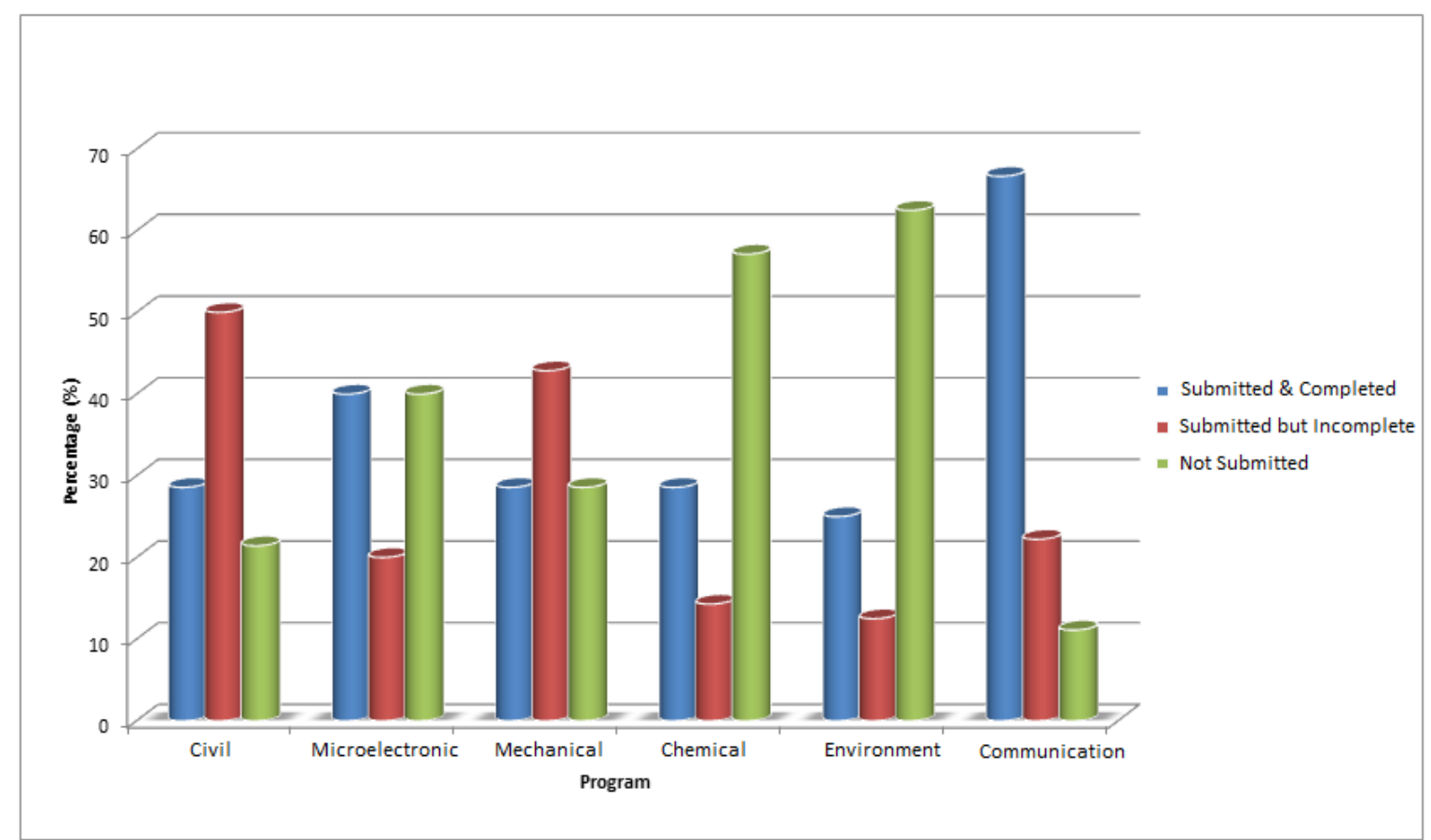

Figure 8. Percentage of teaching folders submission for FKAB 2011/2012 second semester postgraduate courses

Figure 9 shows an increase in teaching folders submission for first semester 2012/2013 FKAB postgraduate courses compared to the previous semester. The performance of teaching folders submission for all six postgraduate programs has increased, and none of the folders was incomplete. Only Environmental Engineering program shows an incline around $9 \%$ in non-submission rate of teaching folders. Mechanical Engineering program achieved $100 \%$ submission of completely filled up teaching folders. This is a very good performance compared to the previous semester which achieved only $28.57 \%$ submission of complete teaching folders. Civil Engineering program also have shown a better performance than the previous semester with a huge $50 \%$ increase of submission. The criteria required for postgraduate engineering program teaching folders are almost identical to the undergraduate, but there are a few items that are not made compulsory. This makes it easier for academic staffs to complete the postgraduate teaching folders. 


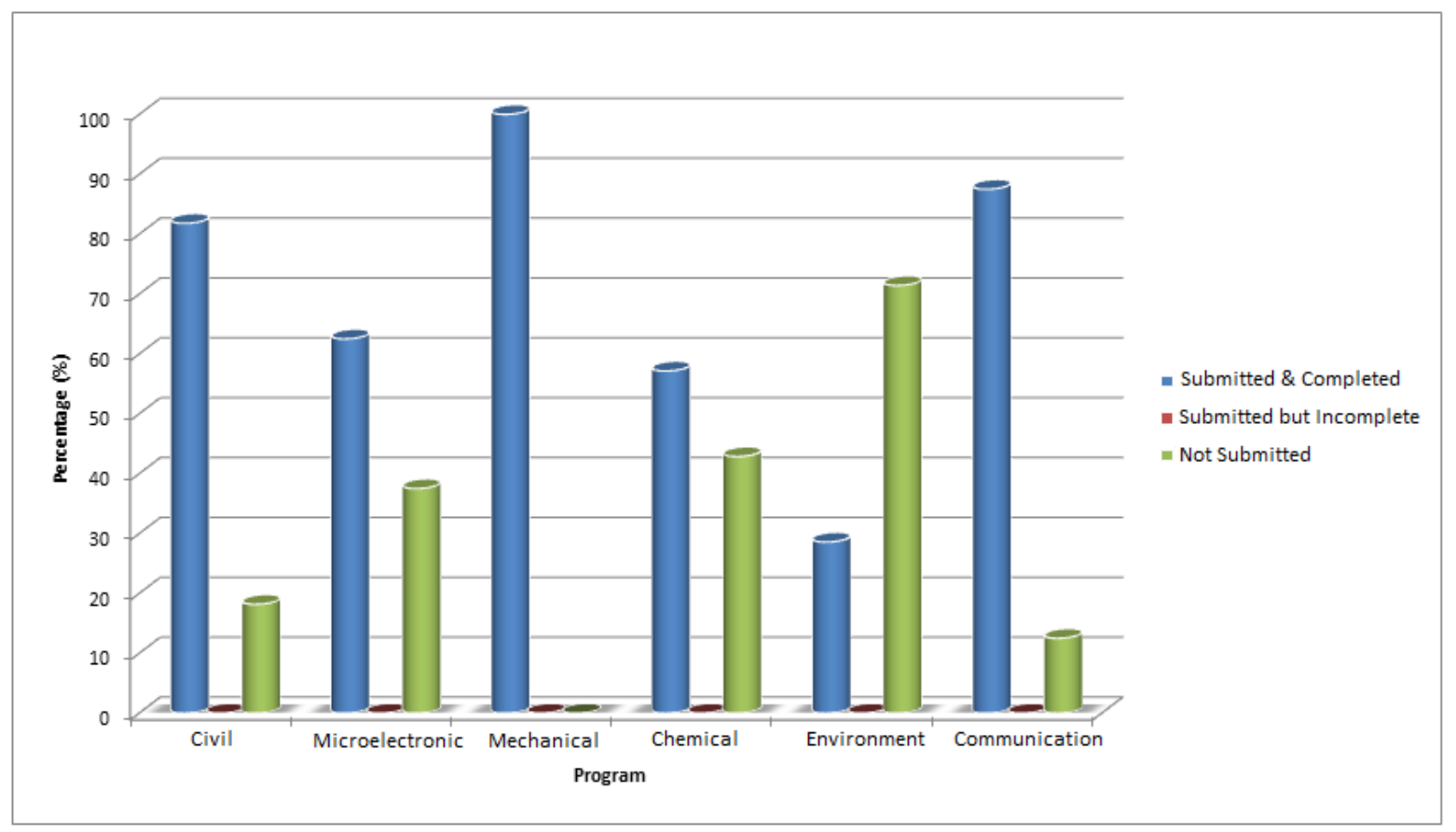

Figure 9. Percentage of teaching files submission for FKAB 2012/2013 first semester postgraduate courses

Numerous achievements have been made even though this new folder management system has been implemented for a few months. There are a lot of aspects that can be improved to obtain better results. For example, the teaching folders which are in hardcopy form should be made into softcopy forms for backup and easier inspection during audit process. The auditors can simply request to ask for whichever folders they want to evaluate by doing simple cross-referencing without having to skim through all the unnecessary folders. This will also reduce the workload of staffs trying to check every single folder to ensure that everything is complete and perfect. A stable computer server is required to ensure the success of this process and avoid system failure. Every submitted teaching folder need to go through a series of screening by the stenographer and other supported staffs to ensure that all materials have been completely attached. Any insufficiency will be reported immediately to the relevant academic staff so that the folders will be completely filled as soon as possible, and will not be procrastinated until the day of the audit. A Quality Awareness campaign week can also be held whereby every staff from the management to support level is required to participate. The event held this will give a huge morale impact on the faculty and institution. An effective communication, cooperation and respect at every level also provide huge contributing factor to achieve a more feasible faculty document management. This will make it possible in future to achieve zero non-submission of teaching folders. This type of mind-set is what the faculty is trying to instil in order to achieve the objective of creating an effective and systematic document management.

\section{References}

Arena, M. (2013). Internal audit in Italian universities: An empirical study. Procedia Social and Behavioral Sciences, 93, 2000-2005. http://dx.doi.org/10.1016/j.sbspro.2013.10.155

Brackin, P. (2002). Assessing engineering education: An industrial analogy. International Journal of Engineering Education, 18(2), 151-156.

Cheng, Y.-Y., Lyu, J., \& Lin, Y-C. (2004). Education improvement through ISO 9000 implementation: Experiences in Taiwan. International Journal of Engineering Education, 20(1), 91-95.

Hernad, J. M. C., \& Gaya, C. G. (2013). Methodology for implementing document management systems to support ISO 9001:2008 quality management systems. Procedia Engineering, 63, 29-35. http://dx.doi.org/10.1016/j.proeng.2013.08.225

Issa, S. S. (2000). Quality assurance of engineering education in private universities in Jordan. International Journal of Engineering Education, 16(2), 158-164. 
Jensen, H. P. (2000). Quality management: Danish engineering education. International Journal of Engineering Education, 16(2), 127-135.

Karapetrovic, S. (2002). Why and how to develop a meaningful quality assurance system in engineering schools. International Journal of Engineering Education, 18(3), 285-294.

Kwok, I. P. K. (2000). Accreditation of engineering degree courses in Hong Kong. International Journal of Engineering Education, 16(2), 154-157.

Malaysian Qualifications Agency. (2008). Code of practice for programme accreditation. Retrieved January 12th, 2013, from http://www.mqa.gov.my

Malaysian Qualifications Agency. (2011). Programme standards: Engineering and engineering technology. Retrieved January 12th, 2013, from http://www.mqa.gov.my

Malaysian Qualifications Agency. (2013). Guideline to good practices: Accreditation of prior experiential learning. Retrieved January 12th, 2013, from http://www.mqa.gov.my

Malaysian Qualifications Agency. (2013). Standard: Master's and doctoral degree. Retrieved January 12th, 2013, from http://www.mqa.gov.my

Paramasivam, S., Mutusamy, K., \& Tan, K. (2013). Study of the effectiveness of the implementation of Washington Accord in Malaysia's engineering undergraduate programme using SEM. Procedia Social and Behavioral Sciences, 90, 803-812. http://dx.doi.org/10.1016/j.sbspro.2013.07.155

Phillips, W. M., Peterson, G. D., \& Aberle, K. B. (2000). Quality assurance for engineering education in a changing world. International Journal of Engineering Education, 16(2), 97-103.

Valdez-Martinez, E., Trumbull, B., Garduňo-Espinosa, J., \& Porter, J. D. H. (2005). Understanding the structure and practices of research ethics committees through research and audit: A study from Mexico. Health Policy, 74, 56-68. http://dx.doi.org/10.1016/j.healthpol.2004.12.014

Zantout, H., \& Marir, F. (1999). Document management systems from current capabilities towards intelligent information retrieval: An overview. International Journal of Information Management, 19(6), 471-484. http://dx.doi.org/10.1016/S0268-4012(99)00043-2

\section{Copyrights}

Copyright for this article is retained by the author(s), with first publication rights granted to the journal.

This is an open-access article distributed under the terms and conditions of the Creative Commons Attribution license (http://creativecommons.org/licenses/by/3.0/). 